\title{
IMPLIKASI TRADISI PATTIDANA PADA SOLIDARITAS UMAT BUDDHA DI DESA PURWODADI KECAMATAN KUWARASAN KABUPATEN KEBUMEN
}

\author{
Oleh: \\ Dewi Agus Sriyani ${ }^{1}$, Tri Yatno ${ }^{2}$, Metta Puspita Dewi ${ }^{3}$ \\ STAB Negeri Raden Wijaya Wonogiri Jawa Tengah \\ dewi25sriyani@gmail.com
}

\begin{abstract}
ABSTRAK
Penelitian ini bertujuan mendeskripsikan pelaksanaan dan implikasi tradisi pattidana pada solidaritas umat Buddha di Desa Purwodadi. Peneliti menggunakan metode penelitian kualitatif deskriptif. Tempat penelitian dilakukan di Desa Purwodadi Kecamatan Kuwarasan Kabupaten Kebumen. Teknik pengumpulan data menggunakan metode observasi, wawancara dan dokumentasi. Keabsahan data peneliti menggunakan triangulasi sumber dan teknik. Teknik analisis yang digunakan terdiri dari mereduksi data, menyajikan dan memverifikasi data. Hasil penelitian menunjukan bahwa: 1) Pelaksanaan tradisi pattidana di Desa Purwodadi dilaksanakan saat peringatan kematian, minggu pertama dan ketiga, dan sepekan penghayatan Dhamma (SPD); 2) Implikasi tradisi pattidana pada solidaritas umat Buddha di Desa Purwodadi yaitu: a) Umat Buddha mempunyai perasaan empati untuk melakukan tradisi pattidana dan membantu mendoakan leluhur; b) Membentuk ikatan kekeluargaan yang akrab dan solid; c) Saling mengingatkan dan memotivasi umat Buddha untuk memahami pattidana yang benar sesuai dengan ajaran Buddha; dan d) Memberikan pandangan benar bagi umat Buddha untuk selalu melakukan praktik pattidana kepada leluhur.
\end{abstract}

Kata kunci: Tradisi, Pattidana, Solidaritas.

\begin{abstract}
The objective of the research is to describe the implementation and the implication of the pattidana tradition in the solidarity of the Buddhist people in Purwodadi village. Researcher uses the descriptive qualitative research method. The place of the research is conducted in Purwodadi village, Kuwarasan subdistrict Kebumen Regency. Techniques for collecting the data are an observation, in-depth interview and documentation. The data validity analysis uses source and technique triangulation. The data analysis technique consists of reducing the data, presenting the data and verifying the data. The research results show that: 1) The implementation of the pattidana tradition in Purwodadi village is carried out at the death anniversary, at the first week and the third week, and at a week of the Dhamma contemplation; 2) The Implications of pattidana tradition in the solidarity of Buddhist people in Purwodadi village are: a) Buddhist people have a feeling of empathy to do pattidana tradition and to help praying the
\end{abstract}


ancestors; b). It shapes a strong and solid kinship tie; c). It reminds and motivates Buddhist people to understand the Buddha's teachings correctly each other; and d) It gives Buddhist people the right view to always practice the pattidana to their ancestors.

Keywords: Tradition, Pattidana, Solidarity.

\section{PENDAHULUAN}

Indonesia merupakan negara kesatuan yang terdiri dari beberapa ribu pulau dan suku, dimana didalamnya terdapat keberagaman budaya. Keberagaman budaya tersebut seperti keberagaman dalam hal bahasa, agama, adat istiadat dan tradisi. Perpedaanperbedaan yang ada dalam masyarakat Indonesia tersebar di seluruh pulau yang dimiliki oleh Negara Republik Indonesia. Pemerintah Indonesia bahkan memberikan kebebasan bagi penduduknya untuk menganut dan mempraktekkan kepercayaan seperti yang tertuang dalam UUD 1945 ayat 2 menyatakan bahwa setiap warga Negara diberikan hak untuk memeluk dan beribadah sesuai dengan agama dan kepercayaannya masing-masing (Suharti, 2013: 24).

Agama yang resmi diakui oleh Indonesia yakni agama Islam, Kristen, Katolik, Hindu, Buddha dan Kong $\mathrm{Hu}$ $\mathrm{Cu}$. Keenam agama tersebut dalam melaksanaan kegiatan keagamaan mempunyai tradisi dan budaya yang berbeda-beda. Salah satunya yaitu agama Buddha. Agama Buddha di Indonesia juga terdapat tradisi, ritual dan tata cara beribadatan yang dilakukan. Menurut Shils dalam Sztompka (2004: p.70) mengatakan bahwa tradisi adalah segala sesuatu yang disalurkan atau diwariskan dari masa lalu ke masa kini. Tradisi yang terdapat dalam agama Buddha sendiri dilakukan dengan melakukan kegiatan keagamaan seperti puja bakti (sembayang), sepekan pendalaman dhamma (SPD), pattidana atau pelimpahan jasa kepada leluhur.

Salah satu masyarakat yang melakukan kegiatan keagamaan pattidana atau pelimpahan jasa adalah umat Buddha di Desa Purwodadi. Menurut Widiyanto (2011: p.26) mengungkapkan bahwa pattidana adalah kegiatan berdana dengan cara pelimpahan jasa kepada leluhur yang telah meninggal dunia. Hal ini selaras 
dengan Subandi (2015: p.28) yang

Berdasarkan

petikan

mengungkapkan bahwa pattidana

Tirokudda Sutta dapat dijelaskan adalah berdana dengan cara bahwa seseorang yang mempunyai pelimpahan jasa. Pattidana juga keinginan untuk melakukan diartikan sebagai memberikan inspirasi pelimpahan jasa atau pattidana kebajikan/kebahagiaan bagi makhluk sebenarnya tidak harus dilakukan lain. Dalam pelaksanaan pattidana atau pelimpahan jasa terdapat cara yang dilaksanakan seseorang untuk dengan mewah dan tidak perlu ritual khusus. Dalam melaksanakan melakukan melakukan pelimpahan jasa baik kepada orang tua maupun sanak keluarga yang telah meninggal dunia. pelimpahan jasa kebajikan ini, hanya perlu melakukan tindakan kebajikan, dan berharap agar kebajikan yang dilakukan akan membuat leluhur ikut Buddha menjelaskan dalam Tirokudda Sutta, Khuddakapatha, Kuddaka Nikaya Jilid 3 (Anggawati, L \& Cintiawati, W, 2006: p.475) yang menjelaskan bahwa dalam melaksanakan pelimpahan jasa atau pattidana dapat dilakukan sebagai berikut:

“... Hari ini mungkin akan memperolehnya, ... Ketika memberikan air persembahan, raja membaktikan jasa kebajikan dengan mengucapkan 'Biarlah ini untuk sanak-saudara'... Ketika memberikan bubur, hidangan, dan makanan, raja juga membaktikan jasa kebajikan tersebut kepada sanak saudaranya dan kemudian ketika raja mempersembahkan pakaian dan tempat tinggal..." merasa bahagia. Pihak penerima jasa kebajikan, dalam hal ini akan mendapatkan manfaat apabila di dalamnya secara emosi terhubung dan kemudian merasa bahagia terhadap kebajikan.

Kegiatan pattidana yang dilaksanakan umat Buddha di Desa Purwodadi sendiri dilakukan setiap dua kali dalam sebulan. Pattidana awalnya dilaksanakan secara rutin dan banyak umat Buddha yang datang untuk mengikuti kegiatan tradisi pattidana, namun kemudian mengalami penurunan jumlah umat Buddha yang mengikuti pattidana. Sebagian umat Buddha memiliki alasan tertentu baik dari faktor internal maupun faktor eksternal, salah satu alasan yaitu 
kurangnya rasa kesadaran dan Terdapat hal lain yang mempengaruhi solidaritas. umat Buddha tidak mengikuti kegiatan

Berdasarkan hasil wawancara pattidana. Hal tersebut disebabkan yang dilakukan peneliti pada tanggal karena adanya solidaritas. Solidaritas 09 Maret 2018, dengan Bapak Saidi seseorang dibentuk dari bagaimana sebagai umat Buddha di Desa cara seseorang memberikan motivasi Purwodadi bahwa dalam pelaksanaan dan dorongan untuk selalu semangat pattidana. Kesadaran dan solidaritas sangat mempengaruhi kegiatan dalam melakukan kegiatan keagamaan pattidana. Hal lain yang menyebabkan seseorang tidak mengikuti kegiatan seperti pattidana sehingga kesadaran dan solidaritas ini sangat diperlukan. pattidana yaitu seseorang lebih Oleh karena itu, solidaritas antara umat mementingkan ego dan kepentingan pribadi masing-masing seperti Buddha atau anggota akan semakin kuat apabila terdapat hubungan timbal balik dan saling memberi. Pengertian duduk/bersantai di warung, tidur, tentang solidaritas, ini selanjutnya menonton film/sinetron yang disukai, diperjelas oleh Dhurkheim dalam dan sebagainya. Selain itu, umat Evantri (2013: p.7) bahwa "solidaritas Buddha kurang tertarik untuk adalah perasaan saling percaya antara mengikuti pattidana. Hal tersebut para anggota dalam suatu kelompok disebabkan sebagian umat Buddha atau komunitas. Apabila orang saling hanya tertarik pada makanan yang percaya maka akan menjadi disajikan oleh pemilik rumah. Apabila satu/menjadi persahabatan, menjadi makanan yang disajikan oleh pemilik saling hormat-menghormati, menjadi rumah tidak sesuai selera umat, maka terdorong untuk bertanggungjawab dan yang datang untuk mengikuti kegiatan pattidana sedikit.

mempertimbangkan kepentingan sesamanya".

Berdasarkan hasil wawancara yang dilakukan peneliti pada tanggal 20 Maret 2018, dengan Bapak Surat sebagai Tokoh Agama Buddha bahwa dalam pelaksanaan tradisi pattidana.

Menurut Soekanto, S (2013: pp.54-55) yang menjelaskan bahwa interaksi sosial adalah kunci dari semua kehidupan sosial karena tanpa interaksi sosial, tidak mungkin ada kehidupan 
bersama. Hampir dari seluruh aktivitas manusia dihabiskan melalui interaksi dalam kelompok, belajar dalam kelompok, dan sebagainya. Melalui kegiatan kelompok, manusia menghabiskan seluruh waktu dalam berbagai kegiatan dan organisasi. Dengan demikian interaksi dan aktivitas kelompok membutuhkan solidaritas.

Solidaritas menurut Tim Redaksi dalam KKBI Pusat Bahasa (2008: p.1328) menjelaskan bahwa solidaritas diartikan sebagai solider, sifat satu rasa (senasib dan sepenanggungan), dan perasaan setia kawan antara sesama anggota sangat diperlukan. Oleh karena itu, solidaritas sangat penting dikehidupan masyarakat terutama dalam melaksanakan tradisi pattidana atau pelimpahan jasa. Apabila solidaritas terdapat dalam umat Buddha ketika mengadakan kegiatan pattidana tentu akan mempersatukan rasa jiwa sosial sehingga menjadi bertambah rukun antar umat Buddha dan mengenal lebih dekat kepribadian maupun karakakter masing-masing.

Berdasarkan permasalahan di atas, peneliti tertarik untuk melakukan penelitian dengan judul "Implikasi
Tradisi Pattidana Pada Solidaritas Umat Buddha di Desa Purwodadi, Kecamatan Kuwarasan, Kabupaten Kebumen".

Tujuan penelitian ini adalah untuk mendeskripsikan pelaksanaan tradisi pattidana yang dilakukan di Desa Puwodadi dan menganalisis implikasi tradisi pattidana pada solidaritas umat Buddha yang dilakukan oleh masyarakat agama Buddha di Desa Purwodadi.

\section{METODE PENELITIAN}

Penelitian yang dilakukan di Desa Purwodadi Kecamatan Kuwarasan Kabupaten Kebumen ini menggunaan metode penelitian kualitatif. Penelitian kualitatif merupakan human instrument, berfungsi menetapkan fokus penelitian, memilih informan sebagai sumber data, melakukan pengumpulan data, menilai kualitas data, analisis data, menafsirkan data dan membuat kesimpulan atas semuanya. Oleh karena itu peneliti "the researcher is the key instrument". Peneliti adalah instrument kunci dalam penelitian kualitatif (Sugiyono, 2013: pp.59-60). Sedangkan jenis penelitian 
ini adalah penelitian lapangan dengan menggunakan pendekatan kualitatif bersifat deskriptif. Penelitian deskriptif menurut Arikunto, S dalam Prastowo, A (2014: p.186) di tegaskan bahwa penelitian deskriptif tidak dimaksudkan untuk menguji hipotesis tertentu, tetapi hanya menggambarkan "apa adanya" tentang suatu variabel, gejala dan keadaan apa yang sebenarnya terjadi menurut apa yang ada dilapangan.

Tempat penelitian dilakukan di Desa Purwodadi Kecamatan Kuwarasan Kabupaten Kebumen. Data dalam penelitian kualitatif ini dikumpulkan melalui observasi, wawancara mendalam, dan dokumentasi. Teknik pemilihan informan dalam penelitian ini menggunakan purposive sampling dengan melakukan wawancara dengan tokoh agama Buddha, sesepuh agama Buddha dan Umat Buddha di Desa Purwodadi. Keabsahan data peneliti menggunakan triangulasi sumber dan teknik. Sedangkan dalam teknik analisis yang dilakukan dalam penelitian mengacu pada konsep Miles \& Huberman yaitu dengan mereduksi data, menyajikan data dan memverifikasi data.

\section{HASIL DAN PEMBAHASAN}

Hasil penelitian terkait deskripsi Implikasi Tradisi Pattidana Pada Solidaritas Umat Buddha di Desa Purwodadi. Data ini diperoleh berdasarkan hasil observasi, wawancara dan dokumentasi yang peneliti lakukan selama di lapangan. Berdasarkan hasil yang dilakukan oleh peneliti dilapangan diperoleh bahwa pelaksanaan tradisi pattidana di Desa Purwodadi dilaksanakan menjadi tiga jadwal kegiatan. Pelaksanaan pertama dilakukan setiap satu tahun sekali ketika menjelang hari raya Waisak. Pelaksanaan kedua yaitu ketika menjelang peringatan kematian 7 , 40/49, 100, dan 1000 hari dan Pelaksanaan ketiga yaitu minggu pertama dan ketiga setiap sebulan.

Pelaksanaan tradisi pattidana dilakukan setiap satu tahun sekali khusus menjelang hari raya Waisak. Umat Buddha berkumpul bersama di vihara untuk membacakan palivacana khusus pattidana atau pelimpahan jasa yang di pimpin oleh romo pandita. Selanjutnya selama membacakan palivacana khusus pattidana atau 
pelimpahan jasa dilakukan dengan yang dilakukan setiap dua kali dalam tuang air oleh romo pandita. Proses sebulan. Buddha dalam Tirokudda pelaksanaan tuang air ini dilakukan Sutta, Khuddakapatha, Khuddaka sampai selesai pembacaan paritta Nikaya (Nanamoli, 2005: p.231) yang pelimpahan jasa berlangsung. Selama menjelaskan bahwa telah diajarkan romo pandita melakukan penuangan air, bagaimana cara pelaksanaan tradisi semua umat yang mengikuti kegiatan pattidana atau pelimpahan jasa ini dalam batin menyebutkan nama masing-masing leluhur yang telah meninggal. Dengan harapan semoga leluhur yang telah meninggal dapat terbebas dari penderitaan dan terlahir di alam yang berbahagia. Kemudian setelah selesai melakukan pembacaan paritta dilanjutkan dengan meditasi dan dhammadesana yang disampaikan oleh romo pandita.

Pembinaan yang dilakukan oleh Bhikkhu kepada umat Buddha di Desa Purwodadi memberikan dampak baik bagi umat Buddha. Dampak tersebut yaitu umat Buddha di Desa Purwodadi memiliki pemahaman yang benar terkait pattidana. Setelah umat Buddha di Desa Purwodadi sudah memiliki pemahaman yang benar tentang pattidana yang sesuai ajaran Buddha. Sehingga kegiatan rutin setiap bulan (anjangsana) di Desa Purwodadi menjadi kegiatan tradisi pattidana rutin pattidana atau pelimpahan jasa dapat dilakukan sebagai berikut: "So they who are compassionate, at heart do give for relatives, such drink and foot as may be pure, and good and fiting at these times". Dari petikan Tirokkudda Sutta dapat dijelaskan bahwa jika seseorang mempunyai keinginan untuk melakukan pattidana maka cara pelaksanaan pattidana dapat dilakukan dengan sederhana. Hal yang paling penting dalam pelaksanaan pattidana adalah niat yang baik dan bersih serta didasari dengan hati yang penuh kasih sayang. Selain itu juga dalam memberikan sesuatu sebaiknya didasari dengan tekad bahwa persembahan tersebut ditujukan untuk memberi dan membantu keluarga atau leluhur yang telah meninggal.

Bentuk pelaksanaan kegiatan pattidana yaitu semua umat Buddha yang hadir dalam kegiatan tersebut membacakan paritta yang dipimpin oleh salah satu umat Buddha yang 
hadir mengikuti kegiatan pattidana. hari besar Waisak di vihara serta dana Acara diawali dengan membacakan yang diberikan yaitu berupa dana uang. paritta avamanggala, kemudian Sedangkan kegiatan rutin pattidana dilanjutkan dengan meditasi serta umat Buddha di Desa Purwodadi dhammadesana yang dipimpin oleh dilakukan di rumah umat secara romo pandita. Seusai ritual pattidana, bergantian (anjangsana) dengan pemilik rumah mempersilahkan umat menyajikan dana berupa makanan. Buddha yang hadir untuk makan yang Selain itu, kegiatan rutin pattidana di telah disajikan. Hal ini dimaksudkan Desa Purwodadi dilaksanakan setiap agar keluarga melakukan perbuatan baik dengan cara berdana makanan kepada umat Buddha yang hadir sebagai praktik pelimpahan jasa.

Masyarakat Buddha di Desa Purwodadi sudah jarang melakukan proses penuangan air sebagai simbol pelimpahan jasa. Secara simbolis umat Buddha melakukan proses tuang air diserahkan kepada pemimpin upacara. Alasannya yaitu karena kebanyakan pemilik rumah atau keluarga sibuk mengurusi tamu dan mengatur makanan yang akan dihidangkan kepada umat yang hadir mengikuti kegiatan pattidana atau pelimpahan jasa. Sehingga proses tuang air tersebut hanya dilakukan menjelang hari besar agama Buddha.

minggu pertama dan ketiga.

Pelaksanaan tradisi pattidana yang dilakukan oleh umat Buddha di Desa Purwodadi berimplikasi terhadap solidaritas umat Buddha di Desa Purwodadi menjadi lebih akrab, solid dan kompak. Solidaritas umat Buddha ditandai dengan keaktifan dalam mengikuti kegiatan tradisi pattidana. Solidaritas umat Buddha juga mendukung untuk saling mengingatkan dan memberi motivasi satu sama lain agar melakukan tradisi pattidana yang benar sesuai ajaran Buddha.

Proses pelaksanaan tradisi pattidana di Desa Purwodadi mengkondisikan umat Buddha untuk saling tatap muka. Dengan sering bertatap muka maka mengkondisikan Kegiatan pattidana yang umat Buddha menjalin komunikasi. dilakukan setiap menjelang hari besar Komunikasi yang terjalin maka akan agama Buddha dilakukan hanya saat timbul persaudaraan dan ikatan 
kekeluargaan diantara umat Buddha menjadi lebih erat. Setelah persaudaraan dan ikatan kekeluargaan semakin erat maka akan timbul antusiasme umat Buddha dalam mengikuti kegiatan tradisi pattidana. Hal tersebut ditandai dengan semua umat Buddha baik orang tua, remaja, anak-anak dan bahkan umat yang beragama turut antusias mengikuti tradisi pattidana.

$$
\text { Umat Buddha di Desa }
$$

Purwodadi juga mempunyai sikap peduli terhadap orang lain. Tujuan dilakukan kegiatan tradisi pattidana di Desa Purwodadi ini adalah untuk membantu mendoakan leluhur agar terbebas dari penderitaan. Sehingga kegiatan tradisi pattidana yang dilaksanakan di Desa Purwodadi dapat membentuk solidaritas umat Buddha menjadi lebih akrab, kompak dan solid. Bentuk solidaritas umat Buddha yang terbentuk ketika melakukan tradisi patidana di Desa Purwodadi meliputi gotong royong, membantu memasak dan dana.

1) Gotong Royong

Membentuk kerja sama merupakan hal yang penting untuk memudahkan, meringankan dan menyelesaikan suatu pekerjaan. Hal tersebut sama seperti yang terjadi pada umat Buddha di Desa Purwodadi ketika melakukan kegiatan tradisi pattidana. Pernyatan ini sesuai yang diungkapkan oleh Bapak Parjo selaku tokoh agama Buddha di Desa Purwodadi sebagai berikut:

"Ketika pelaksanaan tradisi pattidana di Desa Purwodadi, umat Buddha saling membantu satu sama lain. Seperti membantu dan menyiapkan prasarana dan perlengkapan untuk keperluan tradisi pattidana. Selain itu, ada yang bertugas sebagai pembawa acara, pemimpin puja bakti, dan dhammadesana." (Bapak Parjo, Tokoh Agama Buddha, 08 Maret 2018).

Berdasarkan hasil wawancara tersebut dapat disimpulkan bahwa gotong royong sangat berperan dalam membentuk solidaritas umat Buddha di Desa Purwodadi. Hal tersebut sesuai pendapat dari Tim Redaksi dalam KKBI Pusat Bahasa (2008: p.1328) yang menyatakan bahwa solidaritas adalah solider, sifat satu rasa (senasib dan sepenanggungan), dan 
perasaan setia kawan. Salah satu teori yang mendukung umat Buddha di Desa Purwodadi ketika melakukan kegiatan tradisi pattidana adalah memiliki rasa senasib dan sepenangungan. Hal tersebut disebabkan karena umat Buddha merasa bahwa kegiatan tradisi pattidana rutin yang dilakukan setiap dua kali dalam sebulan juga akan terjadi pada umat Buddha lain yang akan melakukan pattidana. Sehingga umat Buddha di Desa Purwodadi saling gotong royong dan membantu menyiapkan prasana dan perlengkapan yang diperlukan untuk keperluan tradisi pattidana. Selain itu umat Buddha juga saling membagi tugas ada yang bertugas menjadi pembawa acara, pemimpin puja bakti, dan dhammadesana.

2) Membantu Memasak

Bentuk solidaritas lain yang terjadi ketika pelaksanaan tradisi pattidana di Desa Purwodadi yaitu membantu memasak. Hal tersebut terlihat bahwa ketika akan dilaksanakan pattidana oleh pemilik rumah. Orang-orang yang berada disekitar rumah berduyun-duyun datang membantu memasak dan mempersiapkan aneka makanan dan minuman. Pernyataan ini sependapat dengan yang diungkapkan oleh Bapak Surat selaku tokoh agama Buddha sebagi berikut:

"Menurut pengamatan saya mba, ketika akan dilaksanakan pattidana oleh pemilik rumah. Para tetangga yang berada di dekat rumah berduyunduyun datang untuk membantu memasak. Selain itu juga membantu mempersiapkan tempat maupun perlengkapan yang diperlukan di altar." (Bapak Surat, Tokoh Agama Buddha, 20 Maret 2017).

Berdasarkan hasil wawancara tersebut dapat disimpulkan bahwa salah satu bentuk solidaritas umat Buddha yang terjadi di Desa Purwodadi yaitu membantu memasak. Hal tersebut juga didukung teori dari Tim Redaksi dalam KKBI Pusat Bahasa (2008: p.1328) salah satunya menyatakan bahwa solidaritas adalah solider dan perasaan setia kawan. Umat Buddha di Desa Purwodadi ketika akan diadakan pelaksanaan tradisi pattidana. Para 
tetangga yang berada disekitar rumah berduyun-duyun datang untuk membantu memasak di rumah yang akan melakukan tradisi pattidana. Sehingga umat Buddha di Desa Purwodadi mempunyai perasaan setia kawan terhadap sesama umat. Selain itu juga disebabkan karena muncul perasaan setia kawan yang terjalin pada umat Buddha di Desa Purwodadi sudah sangat erat, solid, kompak dan bahkan sudah menjadi seperti keluarga. Sehingga tanpa undangan maupun ajakan, orang-orang sudah berduyun-duyun datang dengan sendirinya.

3) Dana

Berdana adalah salah satu cara untuk menunjukan rasa peduli pada seseorang atau pada semua makhluk. Hal tersebut juga dilakukan oleh umat Buddha di Desa Purwodadi ketika akan diadakan pelaksanaan tradisi pattidana. Umat Buddha sudah mempunyai kewajiban untuk memberikan dana berupa uang. Dana uang tersebut digunakan bukan untuk kepentingan pribadi melainkan digunakan untuk keperluan vihara. Dalam hal ini, umat Buddha sudah sepakat dan merupakan keputusan secara bersama-sama untuk memberikan dana berupa uang. Hal ini senada dengan hasil wawancara yang diungkapkan oleh Ibu Kasini selaku sesepuh agama Buddha di Desa Purwodadi sebagai berikut:

"Menurut saya mba, umat Buddha di Desa Purwodadi memiliki rasa solidaritas yang tinggi. Buktinya ketika dilaksanakan tradisi pattidana, umat Buddha mau menerima keputusan apabila pattidana diwajibkan memberikan dana berupa uang. Dan keputusan tersebut dapat diterima dan dilaksanakan sampai sekarang ini." (Ibu Kasini, Sesepuh Umat Buddha, 09 Maret 2018).

Berdasarkan hasil wawancara tersebut dapat disimpulkan bahwa bentuk solidaritas lain yang terjalin pada umat Buddha di Desa Purwodadi yaitu Dana. Hal tersebut juga didukung teori dari Tim Redaksi dalam KKBI Pusat Bahasa (2008: p.1328) menjelaskan bahwa solidaritas berarti solider, sifat satu rasa (senasib \& sepenanggungan) 
dan perasaan setia kawan. Umat tradisi pattidana di Desa Purwodadi Buddha di Desa Purwodadi ketika memiliki respon yang baik dari umat melakukan kegiatan tradisi Buddha. Hal tersebut sesuai dengan pattidana terdapat solider, rasa pernyataan yang dijelaskan oleh Tim senasib dan sepenangungan serta Redaksi Pusat Bahasa (2008: p.1328) perasaan setia kawan yang bahwa umat Buddha di Desa mendukung terbentuknya solidaritas Purwodadi memiliki sifat solider, umat Buddha di Desa Purwodadi. senasib \& sepenanggungan serta Perasaan setia kawan antar sesama perasaan setia kawan antar umat anggota sangat diperlukan untuk Buddha yang terjalin sangat solid dan membentuk kesepakatan bersama kompak. Sehingga menyebabkan umat mengenai dana untuk pelaksanaan Buddha di Desa Purwodadi mempunyai kegiatan tradisi pattidana. Apabila perasaan empati untuk melakukan dan umat Buddha tidak muncul perasaan ikut serta mendoakan leluhur yang setia kawan, solider dan tidak telah meninggal. Meskipun umat sepakat dengan keputusan yang Buddha hanya sekedar mengetahui dan telah ditentukan sehingga memicu belum memahami pattidana yang benar timbulnya konflik antar umat. Tetapi sesuai dengan ajaran Buddha. Tetapi umat Buddha di Desa Purwodadi memiliki sifat solider, sifat satu rasa dan perasaan setia kawan. Sehingga umat Buddha di Desa Purwodadi mempunyai rasa solidaritas yang tinggi untuk membantu dan tidak mempentingan kepentingannya sendiri. Selain itu, umat Buddha di Desa Purwodadi memiliki kesadaran akan kepeduliannya umat Buddha terhadap tempat suci atau viharanya.

Berdasarkan hasil penelitian di atas dapat dijelaskan bahwa keberadaan umat Buddha saling mengingatkan dan memberikan semangat serta motivasi untuk melakukan pattidana yang benar sesuai dengan ajaran Buddha.

Tradisi pattidana di Desa Purwodadi juga dapat membentuk solidaritas Buddha menjadi lebih akrab dan solid baik dalam kekeluargaan maupun kekerabatannya. Hal tersebut ditandai dengan bentuk solidaritas yang terjalin ketika melakukan kegiatan pattidana yaitu umat Buddha saling berinteraksi dan berkomunikasi. 
Sehingga dengan umat Buddha sering bertemu, bertatap muka/face to face, berinteraksi dan komunikasi secara langsung maka menyebabkan umat Buddha muncul ikatan kekeluargaan, kebersamaan dan solidaritas yang terjalin. Hal tersebut sesuai dengan pernyataan yang dijelaskan menurut Soekanto, S (2013: pp.54-55) yang menjelaskan bahwa interaksi sosial adalah kunci dari semua kehidupan sosial karena tanpa interaksi sosial, tidak mungkin ada solidaritas dan kehidupan bersama. Selain itu juga memberikan dampak yang cukup besar bagi umat Buddha di Desa Purwodadi. Hal ini disebabkan karena dengan terciptanya solidaritas umat Buddha. Tradisi pattidana di Desa Purwodadi dapat berkembang mengikuti sesuai dengan perkembangan zaman.

Tradisi pattidana yang dilakukan di Desa Purwodadi juga memiliki pandangan yang benar terkait tradisi pattidana. Oleh karena itu, tradisi pattidana dapat memunculkan rasa kebersamaan dan mendukung umat Buddha untuk selalu melakukan perbuatan-perbuatan baik yang nantinya akan dilimpahkan kepada leluhur yang telah meninggal serta membebaskan leluhur dari alam yang menyedihkan.

\section{KESIMPULAN}

Berdasarkan pembahasan yang telah diuraikan, maka peneliti dapat mengambil kesimpulan sebagai jawaban dari rumusan masalah dalam penelitian ini yaitu deskripsi "Implikasi Tradisi Pattidana Pada Solidaritas Umat Buddha Di Desa Purwodadi” adalah sebagai berikut:

1. Tradisi pattidana adalah kegiatan pelimpahan jasa yang rutin dilaksanakan oleh umat Buddha di Desa Purwodadi. Pelaksanaan tradisi pattidana yang dilakukan di Desa Purwodadi tergatung pada waktu pelaksanaan, dana yang diberikan dan juga tempat pelaksanaan. Waktu pelaksanaan tradisi pattidana setiap dua kali dalam sebulan, peringatan kematian 1-7 hari, 40/49 hari, 100 hari dan 1000 hari serta menjelang hari Waisak. Dana yang dipersembahkan oleh umat Buddha berupa makanan jika dilaksanakan di rumah. Sedangkan dana berupa uang hanya ketika menjelang Waisak. 
2. Implikasi tradisi pattidana pada solidaritas umat Buddha di Desa Purwodadi antara lain: (1) Umat Buddha dapat mempunyai perasaan empati untuk melakukan tradisi pattidana dan membantu mendoakan leluhur yang telah meninggal; (2) Dapat membentuk ikatan kekeluargaan menjadi lebih akrab dan solid; (3) Saling mengingatkan dan memberikan motivasi kepada umat Buddha untuk memahami dan melakukan pattidana yang benar sesuai dengan ajaran Buddha; dan (4) Dapat memberikan pengaruh dan pandangan benar bagi umat Buddha untuk selalu melakukan praktik pattidana/pelimpahan jasa kepada leluhur yang telah meninggal.

\section{DAFTAR PUSTAKA}

Evantri, I. (2013). Studi Solidaritas Sosial (Kasus Lembaga SAR UNHAS). Universitas

Makasar: Makasar.

Prastowo, A. (2014). Metode Penelitian Kualitatif Dalam Perspektif Rancangan Penelitian. Yogyakarta: ArRuzz Media.
Nanamoli. (2005). The Minor Readings ( Khuddkapatha). Oxford: The Pali Text Society.

Soekanto, S. (2013). Sosiologi Suatu Pengantar. Jakarta: PT. Raja Grafindo Persada.

Subandi, A. (2015). Perubahan Bentuk, Fungsi, Dan Makna Tradisi Pattidana Masyarakat Agama Buddha Theravada di Desa Jatisari, Kecamatan Jatisrono, Kabupaten Wonogiri. Tesis. Surakarta: Universitas Sebelas Maret.

(Online: https://digilib.uns.ac.id/.../Peru bahan-Bentuk-Fungsi-danMakna-Tradisi-PattidanaMasyarakat-Agama-BuddhaTheravada-di-Desa-JatisariKecamatan-JatisronoKabupaten-WonogiriCOVER-BAB III-pdf, diakses pada tanggal 15 Oktober 2017).

Sugiyono. (2013). Memahami Penelitian Kualitatif. Bandung: Alfabeta.

. (2013). Metode Penelitian Pendidikan (Pendekatan Kuantitatif), Kualitatif dan $R$ $\& D$. Bandung: Alfabeta.

Suharti, E. (2013). UUD 1945 Hasil Amandemen \& Proses Amandemen UUD 1495 Secara Lengkap. Jakarta: Sinar Grafika.

Sztompka, P. (2004). Sosiologi Perubahan Sosial. Jakarta: Prenada. 
Jurnal Pendidikan, Sains Sosial dan Agama

Tim Redaksi. (2008). Kamus Besar

Bahasa Indonesia Pusat Widiyanto, T. (2011). Pattidana: Jalan Bahasa Edisi Ke Empat. Membebaskan Leluhur Dari Jakarta: PT Gramedia Pustaka Alam Menderita. Yogyakarta: Utama.

Vihara Karangdjati. 